\title{
Moodle HEODAR implementation and its implantation in an academic context
}

\author{
Carlos Muñoz*, Miguel Ángel Conde and \\ Francisco J. García Peñalvo
}

Science Faculty, University of Salamanca,

Plaza de los caídos s/n 37008 Salamanca, Spain

E-mail: carlosmm@usal.es

E-mail: mconde@usal.es

E-mail: fgarcia@usal.es

*Corresponding author

\begin{abstract}
One of the most important aspects of a 'continuously in change' society is to improve everything everywhere. In order to obtain the best products, they should be periodically evaluated and reengineered. So the evaluation task and of course, the adequate results interpretation, can make all the difference between competitors. E-learning is similar to these products. Different issues can be evaluated to make learning process getting better and better, such as tutors, platform software and contents. In this last issue, it can be included the minimum knowledge unit: the learning object (LO) (De Marcos et al., 2008). There exist different models and methods for LO evaluation. What is pretended with this work is to choose one model and implement a singular tool, in order to automatically evaluate these LOs and produce a set of information, that can be used to improve those LOs. In this case, it is implemented in the evaluation model called HEODAR (Morales et al., 2008a) and after that the model is implanted in Studium, the Moodle campus of Salamanca University.
\end{abstract}

Keywords: HEODAR implementation; learning object; LO; evaluation; Moodle; module; agent; JADE; quality; Studium; academic context.

\section{Introduction}

The processes of automation that supports the work of experts in certain subjects, or that even allows for the release of them and their dedication to other tasks, is a constant that has been occurring on an ongoing basis in different spectrum of our society.

This automation has already reached the level of education encompassing all its modalities and many of its processes (empty classroom control, students attendance, rating records and so forth) covering planes like web content evaluation (Marquès, 2000) and multimedia evaluation (Gibbs et al., 2001) which leads to the conclusion that elearning is not out of reach.

More precisely, this article focuses on the study of the current state of the processes associated with the learning objects (LO) evaluation. Also must be considered the implementation of tools which allow processes automation, very important due to the advantages it provides to e-learning, such as tools for learning objects evaluation.

Thus, the evaluation can be considered as the last step of quality LOs management process (Morales et al., 2005), being identified as a cyclical process in which periodic content evaluation by students and experts, reverses in a continuous improvement of LOs stored in appropriate repositories.

The reasons for this study stems from the relevance that LOs are acquiring as portable minimum information units between learning management systems (LMS). There should be methods to evaluate the efficiency and pedagogical quality of these objects for their reuse in different contexts. If an object has reached an optimal adaptation level for a learning activity, it should be used in such activities and not others that may provide a more tangential value. The only way to determine these LOs characteristics is through the 
quality evaluation provided for the students and through real experiences in a platform or a set of platforms.

Obviously, these processes evaluation enhancement, using software tools that automates the entire process or part of it, will represent a clear advantage which will make possible to focus the effort on the main objective: to improve the content and not on the extraction of evaluations results.

Throughout this paper it will be discussed how the evaluation tool is implemented. Firstly, the LOs evaluation evolution and also the evolution of existing software tools to perform this work will be considered. After that, the tool planning and analysis steps will be described. Then, the implantation of the tool on Studium, the LMS of the University of Salamanca, will be described. Finally, following stages in tool development will be talked about, ending with a list of conclusions.

\section{Measuring LOs}

The evaluation task of any kind of entity, component, object or concept has been occurring over time. This technique could be used in several context and always intending to check the quality of the element evaluated and trying to improve it

In e-learning scope, there are many factors that can be evaluated: tutors, students, platforms, documents and so on. Of course, since Los' emergence, these can be added to the list as a feasible element to be improved, analysing the results obtained by the application of appropriate evaluation techniques

From this point of view, several studies have been focused on the acquisition process models and evaluation models that produce the best results and allow LOs improvement in order to achieve greater satisfaction of all actors (students, tutors and of course, content authors).

It can be find processes like cooperative learning object exchange (CLOE), which is based on the content review by content, instructional design and other aspects experts and other processes that rely on systems or repositories with a social and technological fundament, in which evaluators use software tools that guide the processes evaluation like Digital Library Network for Engineering and Technology (DLNET), Multimedia Educational Resource for Learning and Online Teaching (MELROT, 2009) and eLera (2009) through a specific evaluation tool called Learning Object Review Instrument (LORI) (Nesbit, and $\mathrm{Li}, 2004$ ) which propose the result visualisation using ratios, extracted in an automatic form from the actors registered evaluations (Nesbit et al., 2003).

However, in this field of LOs quality evaluation tools, there is no tools which perform this tasks integrated into the most widely used LMS, which contains the majority of such LOs, beyond institutional repositories like the previously mentioned.

That is why it set out the design and development of a software tool that implements an evaluation model. The selected one is the result of Erla Mariela Morales Morgado proposal, explained in her $\mathrm{PhD}$ thesis, the proposal is called Herramienta de Evaluación de Objetos Didácticos de Aprendizaje Reutilizables (HEODAR) which principles (Morales, 2008) where studied and considered as appropriated for being used in an institutional environment: the University of Salamanca, experimentally integrated in a LMS platform with expansion possibility to other existing platforms.

HEODAR contains a wide variety of criteria that aim to promote the LO quality from the more essential pedagogical issues. Criteria are related to logic and psychological meaningfully. The first one is directed to curricula, it means that the LO coherence with the study program: objectives, contents, activities, etc. The second one is directed to the students' characteristics: difficulty level, motivation, interactivity, etc. Each one of these areas aims to evaluate a complete pedagogical LO quality (according to our LOs definition).

The technical criterion aims to complete the LO evaluation as digital resource. As we know, this kind of sources can be composed by different kind of media, for this reason it is very important to consider criteria directed to a variety of them. Our proposal consider the case of the most common multimedia sources: images, video, etc. 
Muñoz, C., Conde, M. Á., \& García-Peñalvo, F. J. (2010). Moodle HEODAR implementation and its implantation in an academic context. International Journal of Technology Enhanced Learning (IJTEL), 2(3), 241-255.

doi:10.1504/IJTEL.2010.033580

\section{$3 \quad$ Project planning}

Among the variety of LMS platforms existing nowadays, it must be taking into account the selection of the optimal platform for an initial integration of HEODAR tool. Due to the recent implantation at the University of Salamanca of a new LMS platform, which is used by teachers and students, it is resolved to implement the tool to woks under such LMS: Moodle. One of the biggest motivations is the possibility of making impact, effectiveness, utilisation and usability studies about the model and also about the designed tool in a practice and guarantied form. It is consider getting these results during the first months after the integration tool process. The results will be used for review and correction.

In addition to these factors, this LMS brings another advantages set over other existing LMS, beyond its use in an academic environment and its use in real formative experiences:

- Moodle is an open source software system.

- Moodle is implemented and maintained by an international community integrated for more than 600,000 members (January 2009 information, http://moodle.org/stats).

- It is currently one of the most successful course management systems (CMS) and there are numerous reports of successful installations in production systems (Kalochristianakis et al., 2008). In fact, Moodle has a base of about 50,000 installed servers around the world (199 with more than 10,000 registered users) in which there is more than 27 millions of inscribed students.

- Moodle is translated to 75 languages (Cole and Foster, 2007).

Moodle is used as the primary LMS in most of Spaniard universities. In Spain, Moodle community is really consolidated and annual congresses are celebrated with great participation grades, especially of every level public and private education centres agents and of company's directives. Nowadays, Moodle is the most popular e-learning environment in Spaniard educative centres and every day, the number of interested companies increased. The versatility and easy to use philosophy, an impeccable community attention and an original business model are the succeed keys (Molist, 2008).

\section{Studying solutions}

Once determinate the platform in which the development and tests are going to be focused on, without undermining its possible expansion to other platforms when the functionality has been thoroughly tested, there is a discussion about the best integration form of HEODAR tool into Moodle.

From a platform point of view, there are several ways to accomplish the utilities integration with Moodle: the incorporation to the Moodle core (as a resource or an activity) or the development of independent tools linked with the platform using data communication techniques.

From a HEODAR point of view and taking into account its collaborative characteristics (Morales et al., 2008b), it does not considered the design and development of the tool as an external complement, but the definition and development as a functional 
element inside the platform that can be deployed on it. Obviously and knowing the HEODAR characteristics, in which appears a clear relation with tutors and content authors, it is finally decided a tool functional an architectonical definition as a Moodle activity module.

\section{Defining the architecture and data sources}

Once the decision regarding the environment and the initial design and implementation form is reached, it starts the study of the different ways to research and define the module architecture.

While the Moodle module definition and schema sets a group of parameters that must be considered in order to obtain a correct integration and working of the module, there are still several aspects to be evaluated. The HEODAR tool succeeds rely on the correct selection of such aspects.

The first one focuses on the data model. We worked on the correct definition of this model towards meeting the needs the evaluation model sets out, but also thinking about how to satisfy other factors suggested by the model authors and that, probably, will constitute a first evaluation model evolution. Such factors should be translated into the data model and are referred to the following characteristics:

- The possibility, not actually considered, of modifying weights that will affect to the calculation process of the evaluation score. These weights are associated to the different evaluation model classifiers. At this moment, in the original evaluation model, every classifier has the same weight.

- To provide intelligent capabilities to the tool, through software agents results analysis. These agents interpret and transmit the process results to the stakeholders (mainly content authors) without the need for them to access the platform and get the information.

Figure 1 Architecture moder (see online version for colours)

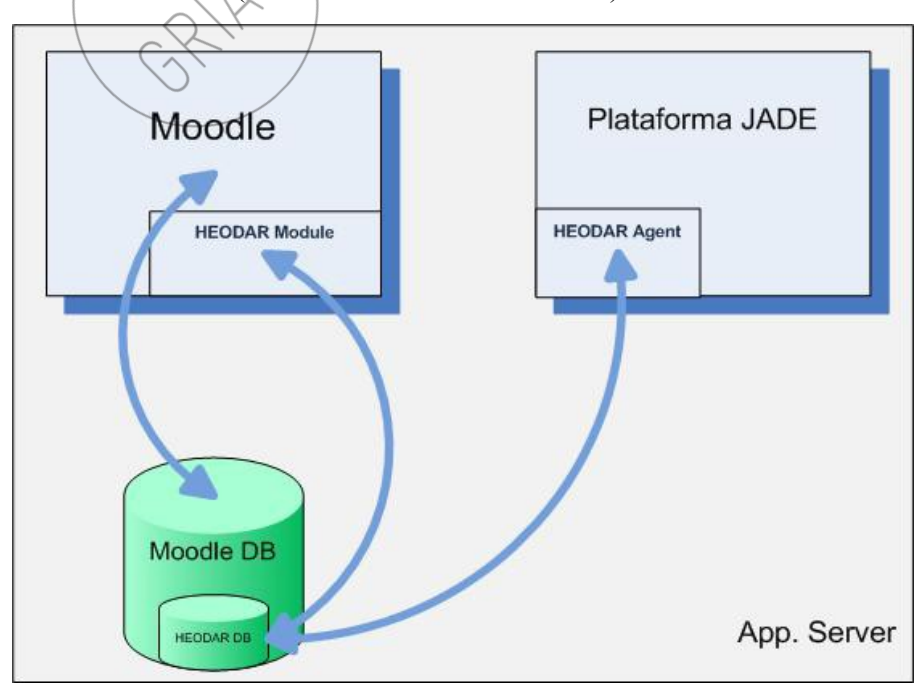


Muñoz, C., Conde, M. Á., \& García-Peñalvo, F. J. (2010). Moodle HEODAR implementation and its implantation in an academic context. International Journal of Technology Enhanced Learning (IJTEL), 2(3), 241-255.

doi:10.1504/IJTEL.2010.033580

This second factor has been considered as really interesting by some content authors, while it represents a tangible improvement on the way in which these authors receive feedback about the quality of its contents. With this information, they may be able to improve them.

Note that the content authors do not usually publish them (especially in a postgraduate and continuing education fields) on one platform (even on homogeneous platforms). In that way, they may find it useful, the existence of an element (agent) that extracts the valuable information about their content and send it to them automatically indicating the origin information platform.

Thus, with the gathered information a definition of the architecture model is made. This model can be observed in Figure 1.

\section{Developing the tool}

In order to implement the two main blocks that constitute the proposed architectural model, the tool itself and the agent system, the project is divided into two phases:

First phase it is constituted for the definition and construction of a stable data model and the implementation and implantation of HEODAR tool as a Moodle module

Second phase it concentrates the effort in the design and implementation of an agent system which provide the module with the intelligent behaviour previously defined and clearly useful for tutors and content authors.

Both phases are integrated into an incremental construction model, which allows putting into operation the first phase resultant product and after certain time, integrating the second phase resultant product, without modifying the working process of the initial module or the stored evaluation result.

Actually, the first phase is carried looking for being incorporated into the Moodle platform of the University of Salamanca (Studium) and perform rigorous tests and impact studies.

\section{Implementing the module}

The functional and information characteristics of the first phase implemented module are adapted to the requested necessities included in the theoretical evaluation model definition. All that information was evaluated in order to define the data model in which the module relies on. This data model can be seen in Figure 2.

It is notable that the incorporation of evaluation questions into the data model responds to an issue indicated in establishing the foundations of the tool itself (Morales et al., 2005). This issue is the possibility that in the future, factors and parameters measured by each of the questions can vary in the future due to the own experience. With this model, the question and classification modification is possible.

This is obviously reflected in the score calculation process implementation for a particular LO evaluation through the evaluation model questions. This calculation 
process must be implemented considering the number of questions of each category and its weights.

Thus, it is possible to define, using the module configuration, the influence weights as seen in Figure 3.

Figure 2 Module data model (see online version for colours)

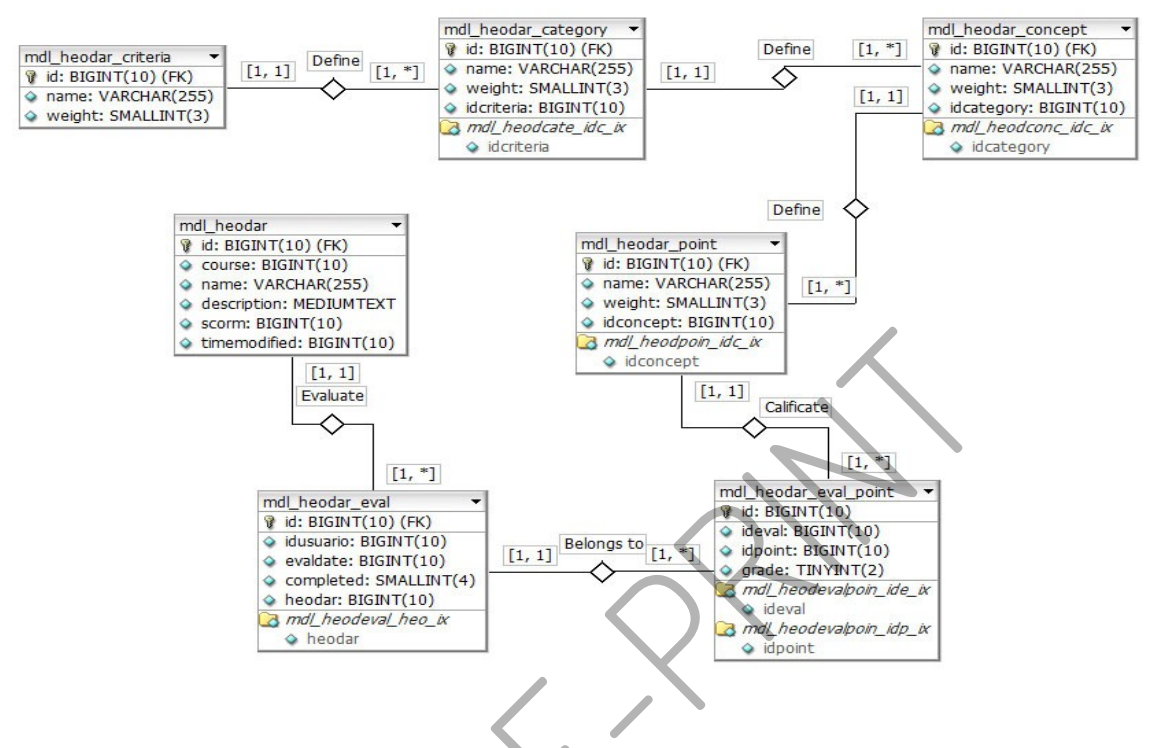

Figure 3 Module configuration (see online version for colours)

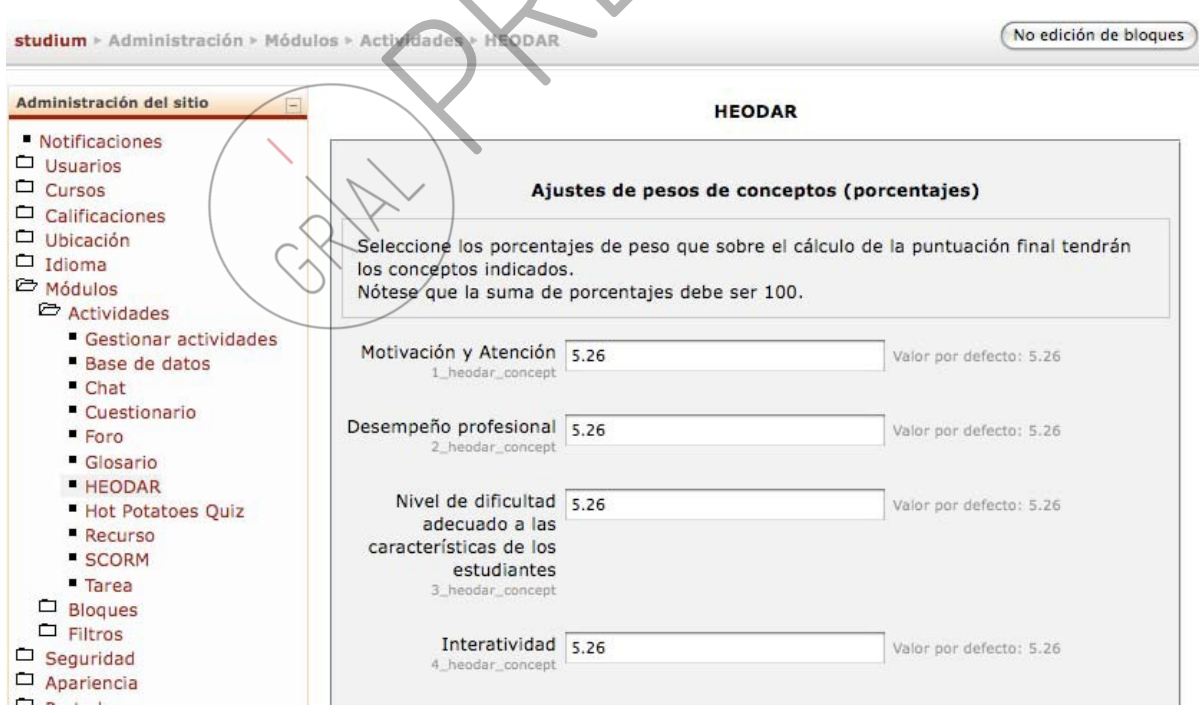

With regard to the configuration of the activity in which this tool is integrated, only minimum information is requested to the creation of an evaluation activity. This information is a name to name the activity in the course, a description and one of the 
Muñoz, C., Conde, M. Á., \& García-Peñalvo, F. J. (2010). Moodle HEODAR implementation and its implantation in an academic context. International Journal of Technology Enhanced Learning (IJTEL), 2(3), 241-255.

course LOs. These LOs are obtained from available platform data for the course in which the activity is being configured. An example could be shown in Figure 4.

With regard to evaluation display, this is represented as a test to each of the participants of the course. The factors are classified and presented according to the data definition, making easy the completion of each of the factors, which evaluation levels are specified in the theoretical definition of the tool. Figure 5 shows an example of such representation.

Figure 4 Module instantiation (see online version for colours)

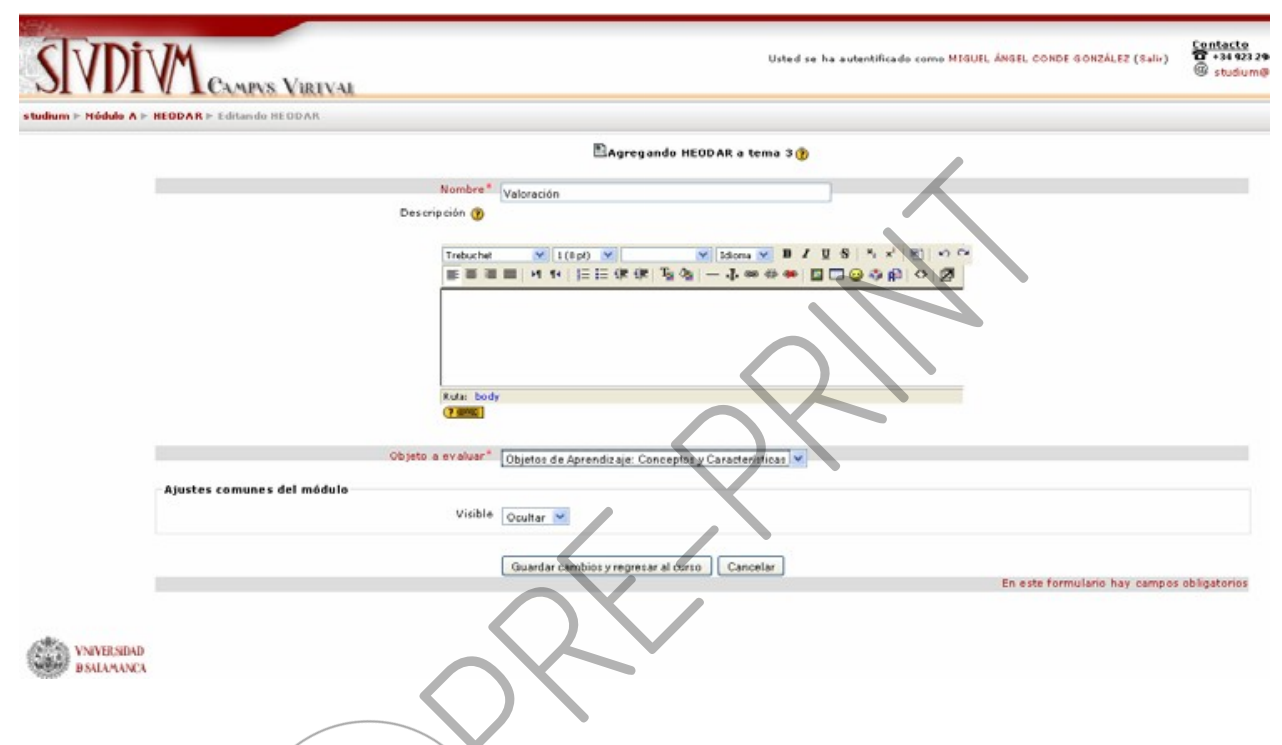

Figure 5 Evaluation form (see online version for colours)

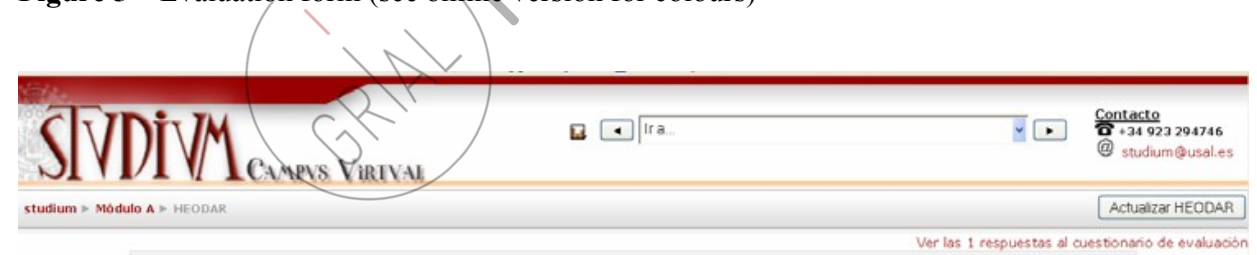

Criterios Pedagógicos 
Initial definition of displaying results (Morales et al., 2008b) is extended by adding some new ways of visualisation. Additionally to a graphical results display and its related explanation, a categorised display of results will be included

As previously been commented, both the concepts and assessment categories could be changed in terms of their quantity, so methods and algorithms to display results should consider these facts.

Considering visual information representation, is implemented the same representation as those initially defined for each part (Figure 6). Thus, the representation is done by using five-star rating scale, from one to five, either by value or weighted value.

Using first method to calculate results requires considering two parameters: total number of measurable concepts and the weight of each concept.

Figure 6 Results meaning (see online version for colours)

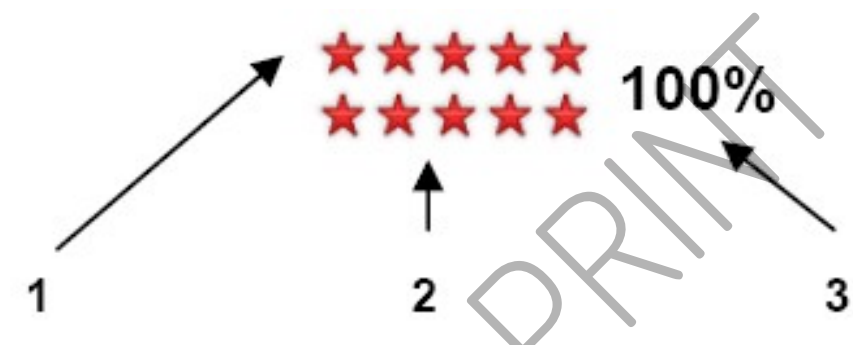

Learning object assessment is divided in three parts:

- The representation of the average results of all LO evaluations. This will be considered the evaluation of a LO. For its calculation must be applied weights recovered from the module configuration for each of the concepts defined, as shown in Figure 7. To calculate the results, using this first method, two parameters must be considered: the total number of measurable concepts and the weight of each concept. This procedure ensures that the calculation will be adjusted to any new concept that can be added. Also this method will be independent of concept classification because classifiers are not involved in the process. The algorithm will be integrated in a calculation method for each user, so later arithmetic average of the results returned will be considered.

Figure 7 Algoritmo de cálculo de resultado (see online version for colours)

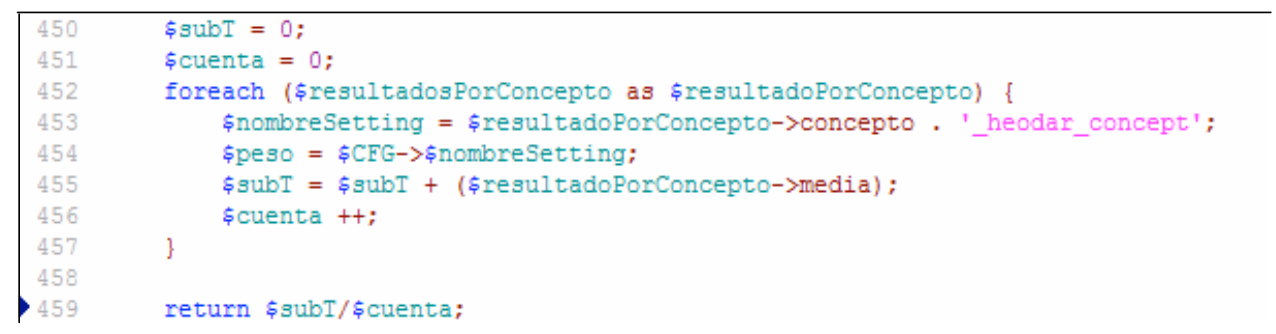


Muñoz, C., Conde, M. Á., \& García-Peñalvo, F. J. (2010). Moodle HEODAR implementation and its implantation in an academic context. International Journal of Technology Enhanced Learning (IJTEL), 2(3), 241-255.

doi:10.1504/IJTEL.2010.033580

- The valuation representation is calculated by multiplying the percentage of teachers who have assessed the LO to the total of teachers, resulting in the weighted assessment. Total number of teachers is obtained through existing procedures proposed by Moodle platform.

- Percentage of teachers who have assessed the OA with respect to total teachers. To obtain the necessary calculation parameters obtained values from one and two are also used.

In addition to this presentation, it adds another in which results are displayed grouped by categories, as shown in Figure 8, which includes the display of all forms of representation of results implemented. It must be considered the legend included to clarify the visual representation meaning, in a way in which initial users could understand properly the different concepts involved in evaluation processes. This second way to present results consists of the four bottom lines shown in the figure. There is also information related to each concept category. Actually considered categories are those included in HEODAR definition (Morales, 2008).

At this point the values calculation does not consider the evaluation weights. Results displayed for each category are calculated as the arithmetic average of the valuations of the terms contained in that category.

Figure 8 Result visualisation (see online version for colours)

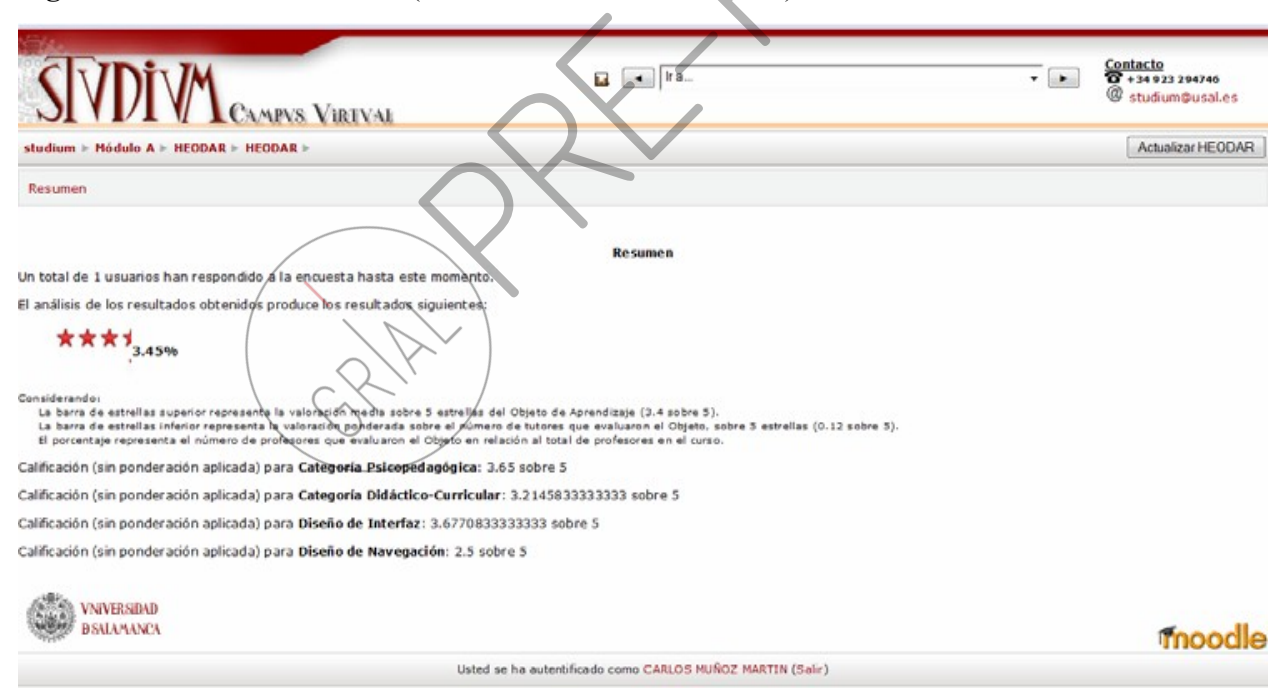

Regarding displaying permissions, any user enrolled in a course can view the results assigned to the objective of learning assessed once user particular assessment has been submitted and never before. There is an exception for those users who have the role of editing activity, by default assigned to tutors and administrators.

Results suitability is going to be evaluated by using a forum. This forum will be integrated in the LMS Studium. 


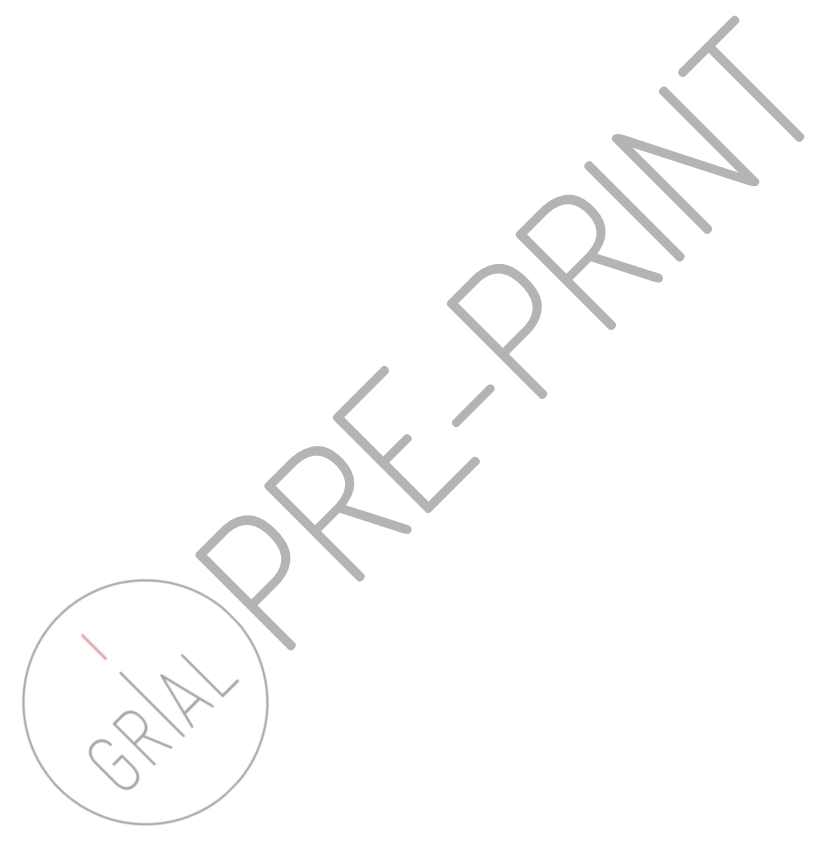




\section{Installing HEODAR in Studium}

Studium is presented as the official platform for online training at the University of Salamanca (http://studium.usal.es). Some of the main Studium objectives are:

- provide support for all the its studies: degree, graduate, doctorate degrees and continuing education

- provide a set of value added services through an institutional portal that also serves to provide access to virtual campus

- provide methodological advice and training to teachers at the University of Salamanca

- promote quality plans for the improvement of the tools available to the university community for the online training

- maintaining and developing the virtual campus, with both updates and its own developments as well as joint research projects of the Virtual University research groups, companies and other institutions.

Studium has begun to be implemented from November 2008 with the aim of improving the university community services provided by the previous platform Moodle called Eudored.

Since then, Studium has experienced a remarkable growth. In less than five months, it almost doubled the number of implemented courses for official degrees, such as the total open spaces for teachers.

The ratio of spaces for official degrees and total spaces since 2007 is maintained and even increased the number of total subjects with respect to officers, which indicates that teachers use the space for other Studium purposes and practical courses extraordinary spaces experimental and therefore, the penetration of the virtual campus is growing.

An initial installation of the tool in this platform has made in order to make it accessible as an activity of this platform.

HEODAR has been implemented in Studium to support an activity of a Master in Computer Science where students are involved with the role of teacher in order to have the possibility to create an actiyity that allow them to add HEODAR to assess the quality of LO, which have been packaged with SCORM format.

The set of developed files has been prepared according to the specifications proposed by the Moodle development community, to allow the proper installation of the module.

Thus, a folder named 'heodar' was placed under the Studium Moodle installation 'mod' directory.

The second step was the automatic installation process of the module, using the notification link under the Moodle administrator menu. All the process was completed successfully, including the Moodle data model actualisation, which include the new tables creation and the insertion of initial data on them, as is explained in Section 6.

With all this premises, we can conclude that the installations process was completely successful. Furthermore, it is checked that the developed module is now available in the list of activities. At this point the tool is already configured in order to be used in every platform context. 


\section{Results}

The first of the learning activities, which is considered as a real test of how this module works, is a learning module in the Master in Computer Science developed by University of Alcalá. In this module, students have tutor role and they must configure and create an HEODAR instance to evaluate a LO. Following this activity and the extraction of results that can be seen in Figure 9, the evaluation of the user experience by using an ad-hoc quiz will be the next step.

Regarding to usability of the tool, results are satisfactory, maximum stipulated values are not reached. The analysis assumes that the establishment of the form, the organisation of concepts to evaluate and format are not an impediment to understand and achieve the ultimate goal of the tool.

Figure 9 LO evaluation results (see online version for colours)

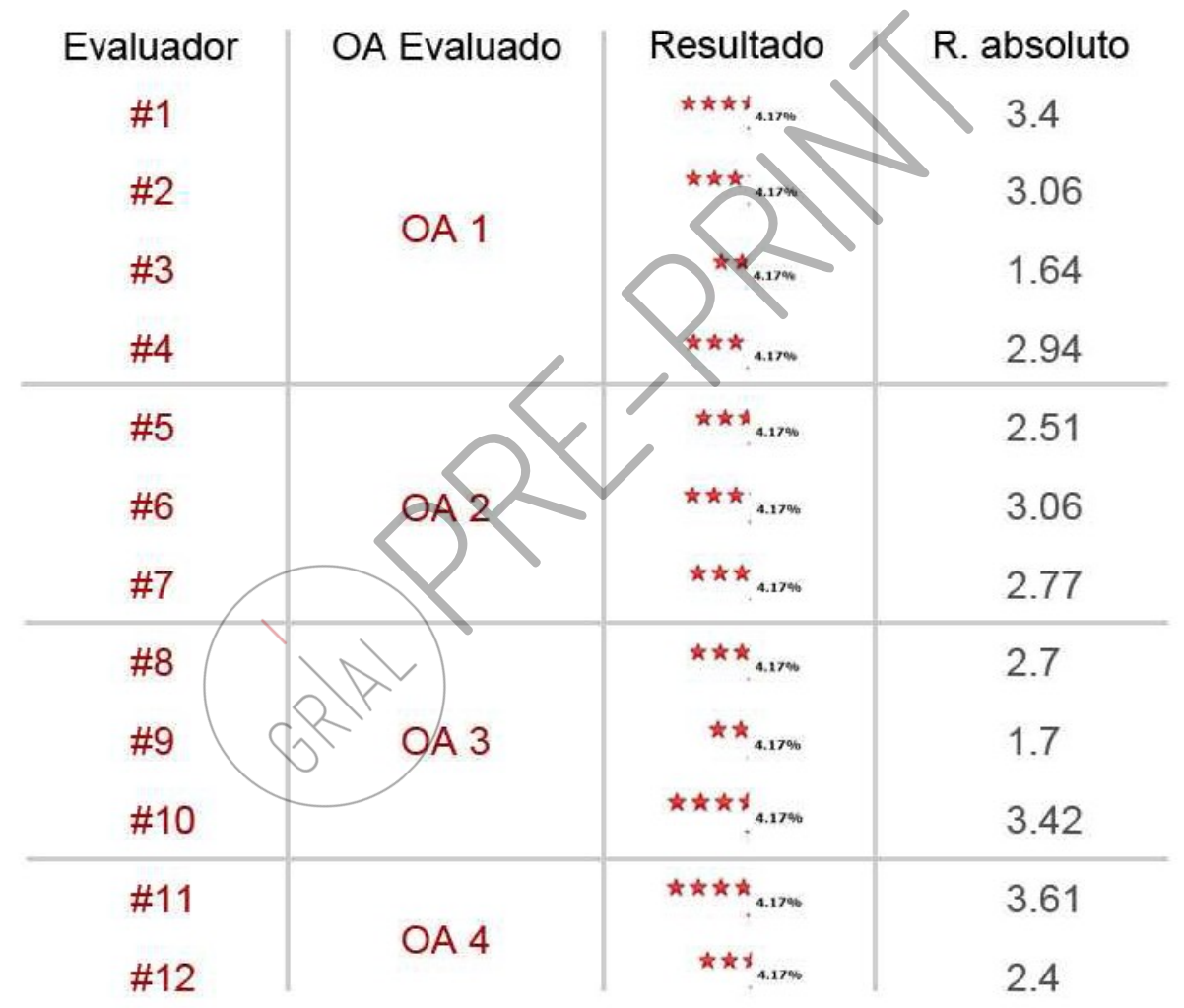

Regarding the quality and result visualisation format, getting after evaluation task, it is a worst pointed characteristic in comparison with the previous one because of several points given by users which are related with the possibility of adding more advanced graphic information for result analysis improvement and the possibility to classify strong factors and worst factors using two limits. 
The latest close question asks about the possibility of sending information through e-mail or mobile device using SMS protocol. This initiative positively evaluates, so it will be take into account in future adaptations of the tool.

Particularly, it is considered as relevant opinion of a tool user who is experimented in managing LOs. This comment expose what constitute the main investigation work objective which consider and takes the fundaments of existing model and tools for evaluations: "A very good took that supposes and important advance in comparison with another existing tools, but less exhaustive, like LORI or the LO evaluation of MERLOT".

Finally, and considering the propositions obtained through the evaluation form, several characteristics of the tool are improved:

- Font size: less ratio of font sizes for the texts in the module.

- Best and worst evaluation points: result visualisation of the best and worst evaluated characteristics of the LO using the established limits which are 1.5 for the worst and 4.5 for the bests (over five). The reason for not using symmetric limits is that the most important task is to know the worst points and only the extraordinarily good points for improve and expand them respectively.

\section{Future work}

Once the module resulting from the development of the first phase is integrated, following steps should be, the recovery and analysis of the first data released from the module use in Studium and the beginning of the development of the second stage.

In an initial evaluation made about the different techniques that allow the implementation of considered behaviour, the best option is working over a JADE agents platform. This platform will be the base of the implementation and integration of a set of agents which autonomously do the following tasks:

- periodic retrieval of information gathered through the tests

- processing and transmission of information analysed and transformed to the contents authors.

Obviously, there is a system configuration that will allow agents to identify those environments (platforms) on which the use of this system is possible. Also, they were allowed to access to the appropriate stored data, obtained through the module evaluation.

There are several attempts to integrate an LMS platform with a system of agents in order to provide a degree of intelligence to this system (Scutelnicua et al., 2007). Considering Moodle LMS, some initiatives and integration trials has been made, among which, forums will be enhanced. This integration was the addition of some new parameter to the forum and which allows the definition of the communication way between agents and the platform. Those parameters include the option to enable or disable the use of information by the system of agents in order to prevented external queries. Another important parameter is the frequency with which the agents carry out the tasks entrusted to it.

All these parameters can be exported to the system of agents focused on a JADE platform. This is because there are evidences of the potential for integration and operation of that exportation. 
The result, once developed, will be added to the module already produced and put into operation in the platform Studium of the University of Salamanca.

\section{Conclusions}

Considering evaluation of learning objects and its related processes, HEODAR implementation could be seen as an example that changes this preceding way. This is because we can evaluate learning elements in a different context. This context is directly where teachers and students use them, in a LMS.

The integration as a Moodle module has resulted in a success due to the possibility of it integration in the platform for online teaching of the University of Salamanca. Since that integration, results will begin to be extracted from the data generated by the assessments of the actors involved on that platform. This information will be used for the improvement of LOs stored in repositories of that university.

This represents an important advantage in comparison with those which have not yet integrated the developed module; this is because it allows continuous improvement of content, which is expected to increase satisfaction among students. This fact will be confirmed by the better grades granted by evaluators to all that reevaluated objects.

Also, focusing mainly on intelligent systems for communication with the authors of content, it will be made a substantial improvement in the implementation of HEODAR, which impact will be measured by comparative studies between the results obtained in the initial stage and those obtained after the integration of the second phase of development.

According to this, on of the most important issue about HEODAR methodology is the incorporation of a value that reflects the quality of LOs and details about their implementation on the basis of the LOM metadata considering the element '9.clasification'. It is explained how the quality of LOs are valued from diverse points of view. The obtained valuation is translated into a number that allows that they should be catalogued in a context attending to the element of metadata mentioned before. This proposal allows the incorporation of the quality in the LOs management, it means the definition of ontologies for a domain facilitating their search and cataloguing process. Hereby, the metadata can be used not only to look for, but also to value and to access to those who have been considered like of quality.

The quality of learning is conditioned to, among other factors, the quality of content and the quality of LOs, such as basic units of knowledge. Also implementations and evaluation techniques must be considered, as a way to improve learning quality and thus the satisfaction of students and tutors. This is the reason because the evaluation and its application in real contexts are so important to improve learning processes.

\section{References}

Cole, J. and Foster, H. (2007) Using Moodle, 2nd ed., O’Really.

De Marcos, L., Martínez, J. and Gutiérrez, J. (2008) 'Particle swarms for competency-based curriculum sequencing', WSKS, pp.243-252.

eLera (2009) Simon Fraser University, Surrey, British Columbia, Canada, http://www.elera.net. 
Gibbs, W., Graves, P. R. and Bermas R. S. (2001) 'Evaluation guidelines for multimedia courseware', Journal of Research on Technology in Education, Vol. 34, No. 1, pp.2-17.

Kalochristianakis, M., Paraskevas, M. and Varvarigos, E. (2008) 'Asynchronous tele-education and computer-enhanced learning services in the Greek school network', WSKS (1), pp.234-242.

Marquès, P. (2000) 'Criterios de calidad para los espacios web de interés educativo', available at: http://decroly.org/escola/formacio/criterios_\%20calidad_web_educ.pdf.

MERLOT (2009) http://www.merlot.org/.

Molist, M. (2008) 'Moodle llena la geografía educativa española de campus virtuales', Diario el Pais, available at: http:/www.elpais.com/articulo/portada/Moodle/llena/geografia/educativa/ espanola/campus/virtuales/elpeputec/20081204elpcibpor_1/Tes.

Morales, E. (2008) 'Gestión del conocimiento en sistemas eLearning', Objetos de Aprendizaje, Cualitativa y Pedagógicamente Definidos, University of Salamanca, Salamanca, Spain.

Morales, E., García, F., Barrón, A., Berlanga, A. and López, C. (2005) 'Propuesta de evaluación de objetos de aprendizaje', II Simposio Pluridisciplinar Sobre Diseño, Evaluación y Descripción de Contenidos Educativos (SPEDECE).

Morales, E., García, F., Barrón, A., Rego, H. and Moreira, T. (2008a) 'Learning objects for eLearning systems', WSKS (2), pp.153-162.

Morales, E., Gomez, D.A. and Garcia, F.J. (2008b) 'HEODAR: herramienta para la evaluación de objetos didácticos de aprendizaje reutilizables', SIIE’08, Salamanca, Spain.

Nesbit, J., Belfer, K. and Leacock, T. (2003) Learning Object Review Instrument (LORI) User Manual E-Learning Research and Assessment Network.

Nesbit, J.C. and Li, J. (2004) 'Web-based tools for learning object evaluation', International Conference on Education and Information Systems: Technologies and Applications, Orlando, Florida.

Scutelnicua, A., Linb, F., Kinshukb, Liuc, T., Grafd, S. and McGrealb, R. (2007) 'Integrating JADE agents into Moodle', Proceedings of the International Workshop on Intelligent and Adaptive Web-based Educational Systems (IAWES), Hiroshima, Japan, pp.215-220.

Studium, Unversity of Salamanca (2008) http//studium.usal.es.

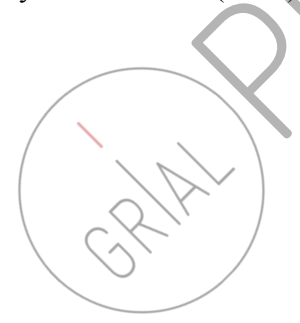

